\title{
Relapse and short sickness absence for back pain in the six months after return to work
}

\author{
Claire Infante-Rivard, Monique Lortie
}

\begin{abstract}
Objectives-To measure the incidence of back pain relapse (causing three consecutive days off work on medical advice) and of short sickness absence (less than three consecutive days), and to determine whether the incidence of such events was affected by overall pain and specific pain related to simple daily movements (functional capacity) assessed at discharge.

Methods-A cohort of workers with a first compensated episode of back pain was prospectively followed up from return to work after rehabilitative treatment. Follow up among 230 workers was carried out monthly by phone for a maximum of six months. Crude and adjusted rate ratios (RRs) along with $95 \%$ confidence intervals $(95 \% \mathrm{CIs})$ were estimated with the Cox's proportional hazards model.

Results-Within six months of return to work, 29 workers $(12 \cdot 6 \%)$ had relapsed, and another 15 workers (6.5\%) had a short sickness absence. $50 \%$ of relapses had occurred within 42 days of return to work whereas this figure was 28 days for short sickness absence. In a multivariate model that considered pain and clinical variables at discharge only a scale combining all pain variables (specific daily movements as well as the visual analog overall pain scale) contributed to relapse and short sickness absence as the outcome (RR (95\% CI)) (1.53 (0.96-2.43)); the same was true in a model considering pain and workers' views on desired changes to work conditions $(1.60 ; 1.08$ to 2.36).

Conclusions-Incidence of relapse or short sickness absence in the first six months after return to work was $19 \cdot 1 \%$. Of all measured prognostic variables (sociodemographic, clinical, workers' views, and pain), only overall pain and pain associated with carrying out simple daily movements were helpful in predicting relapse or short sickness absence.
\end{abstract}

(Occup Environ Med 1997;54:328-334)

Keywords: back pain; relapse; prognosis

Natural history and clinical course of back pain are still incompletely documented. ${ }^{1}$ This finding is particularly true for the incidence of relapse after a first compensated episode of back pain as no estimates from cohort studies for this particular group of subjects were found in the published literature.

Two recent reviews on back pain ${ }^{12}$ briefly assessed recurrence by referring to work by Berquist-Ullman and Larsson ${ }^{3}$ in 1977 , and by Troup et $a l^{4}$ in 1981. The first group 3 carried out a prospective treatment trial among 217 workers at Volvo in Sweden. Among these workers $57 \%$ reported previous episodes; however, a pain free year before the onset of the current episode was an admission criterion, and $83 \%$ had had back pain for less than three weeks when they entered the trial. A relapse was recognised if the initial episode had subsided and the worker had continuous or episodic pain in his back every day. Six months after recovery, $21 \%$ had a recurrence, but after one year, this figure was $62 \%$. Among all study subjects, $31 \%$ had to take time away from work for a recurrence during the first year after recovery. Troup et $a l^{4}$ carried out a study to identify prognostic factors in workers who had experienced back pain. Subjects entered the study when they were examined at their medical centre after an episode of back or sciatic pain, on return to work after sickness absence, or for those not absent from work, when they reported a back injury sustained at work. Follow up was carried out with a postal questionnaire, one and two years after entering the study. Out of the 802 studied workers, $502(62 \%)$ reported previous episodes with sickness absence. The average duration of sickness absence for the current episode was seven weeks. Most subjects were treated with bed rest and analgesics. At the time of examination, $78 \%$ had returned to work but only $30 \%$ said they were pain free. Sickness absence was reported by $44 \cdot 3 \%$ of workers during the first year after they had been examined, and $48.5 \%$ were sent for treatment. Finally, with computerised Québec Compensation Board files, Abenhaim et $a l^{5}$ estimated that after appearing in the files in 1981 for a compensated episode of back pain, $22 \%$ of subjects were again compensated with a similar diagnosis in the next year, whereas this proportion rose to $36.5 \%$ in the three subsequent years. Subjects appearing in the files in 1981 could have had any number of episodes of back pain in their working life and the authors could not determine whether there was a relation between the previous and current episode.

We carried out a treatment inception cohort study of workers with a first compensated episode of back pain which was severe enough so that the worker went into rehabilitation 
treatment; they entered the cohort at the beginning of treatment soon after the work accident. They were first followed up for time to return to work. ${ }^{6}$ From return to work, they were followed up for six months for the occurrence of the first relapse or the first short sickness absence due to back pain. Relapse was defined as back pain causing three consecutive days off work with medical advice; short sickness absence for back pain was defined as absenteeism lasting less than three consecutive days.

The main goal of the study was to measure the incidence of first relapse and of short sickness absence due to back pain, and to determine whether the incidence of such events was affected by overall pain and specific pain related to simple daily movements (functional capacity) assessed at discharge.

\section{Methods}

Methods have been described in detail elsewhere. ${ }^{6}$ Briefly, between November 1988 and May 1992, 829 workers who had been compensated for low back pain presented at two Québec Health and Safety Commission designated centres in Montréal for rehabilitative treatment. Treatment is recommended by the worker's physician and must be accepted by a Québec Health and Safety Commission physician. At eligibility screening, when workers presented at the treatment centres, workers who reported a back pain episode in the past five years which kept them away from work for more than one day or bedridden for two consecutive days were excluded if they were not working at that time. There were 402 eligible subjects (48\%); among them, 305 (76\%) agreed to participate in the study and went on to complete their treatment. This report is about the 230 workers who returned to work after treatment. Their mean (SD) sickness absence for the current episode before return to work was 126 (137) days.

Sociodemographic and work environment characteristics were measured at baseline with a face to face interview. When the worker was medically discharged after conventional rehabilitation treatment, the following measures were taken; the physiotherapist-interviewer administered a series of questions about pain when carrying out simple daily movements related to functional capacity such as standing up waiting for the bus, climbing up and down the stairs, sleeping, walking, washing at a sink, etc. The answers were on the following scale: no pain, little, some, much, impossible to carry out because of pain. We also used a visual analog scale to measure overall pain, ${ }^{7}$ presenting a horizontal line with at one end the score 10/10 and the words "the most intense pain that can exist", and at the other end, a score of $0 / 10$ with the words "no pain at all". The physiotherapist measured flexion amplitude with a goniometer: good flexion was defined as being in the upper $25 \%$ of the normal distribution, excluding missing values. Symptoms were reported in the medical record so it was possible to determine whether the patient had the following: pain radiating in each leg, to the buttock, up to the knees, the heel, or the toes; neurological symptoms such as sensory deficit, muscular weakness, and slower reflexes; and finally, limitation in the amplitude of movements as observed by the physician. In the analysis, the variables "pain radiating" and "neurological symptoms" were defined as present if positive in any of the categories listed and negative otherwise. We also found from the medical record whether the treating physician advised work restriction at discharge.

Follow up procedures were carried out on the phone by the therapist involved with the worker since the entry into the study: a first contact took place about a week to 10 days after discharge. Then the worker was contacted every month for six months, or until a first relapse occurred, or the worker was lost to follow up, whichever occurred first. Short sickness absences due to back pain were also measured at each interview; for those reporting such episodes, follow up continued until relapse or the end of the study. Although workers were interviewed on their work and difficulties at each follow up, we report here on answers taken from the first interview. At that time, workers were asked if they had returned to the same workplace, the same job, and the same working conditions. If they had returned to the same company and the same job, they were asked about changes in the working conditions such as quantity of work required, tasks, and the work itself; then they were asked if they found these changes satisfactory. If they changed company or type of work, they were asked if the reason was back pain. Finally, we asked the workers if they thought that they should have been offered another job, if their job should have been physically modified, if certain tasks should have been eliminated, or their work reduced with the possibility of more pauses.

\section{STATISTICAL ANALYSIS}

Relapse (and time to relapse) within the first six months after return to work as well as first short sickness absence due to back pain were the outcomes analysed. Also, an analysis was carried out in which time to relapse or to first short sickness absence due to back pain was the outcome of interest. That was possible because none of the workers with short sickness absence due to back pain had a relapse within the study period, so the events were independent. A Kaplan-Meier survival curve was estimated to describe the probability of relapse or first short sickness absence due to back pain in relation to time since return to work. A Cox's proportional hazards regression model was used to assess the independent contribution of relevant variables to the probability of these events (relapse alone, first short sickness absence due to back pain alone, and a combination of the two). The $-2 \log$ likelihood statistic was used to assess the contribution of a variable to the fit of the data. A P value $<0.10$ for this statistic in the univariate analyses was the criterion to include the vari- 
Table 1 Study follow up duration from return to work among cohort members

\begin{tabular}{lccr}
\hline & Subjects & \multicolumn{2}{c}{ Follow up in days } \\
\cline { 4 - 5 } Outcome & $n(\%)$ & Median & \multicolumn{1}{c}{ Range } \\
\hline Relapse & $29(12 \cdot 6)$ & 42 & $1-164$ \\
First short sickness absence due to back pain & $15(6 \cdot 5)$ & 28 & $1-182$ \\
Neither relapse nor short sickness absence & $155(67 \cdot 3)$ & 184 & $184-4$ \\
Returned to work but lost to follow up & $31(13 \cdot 4)$ & 71 & $1-176$ \\
\hline
\end{tabular}

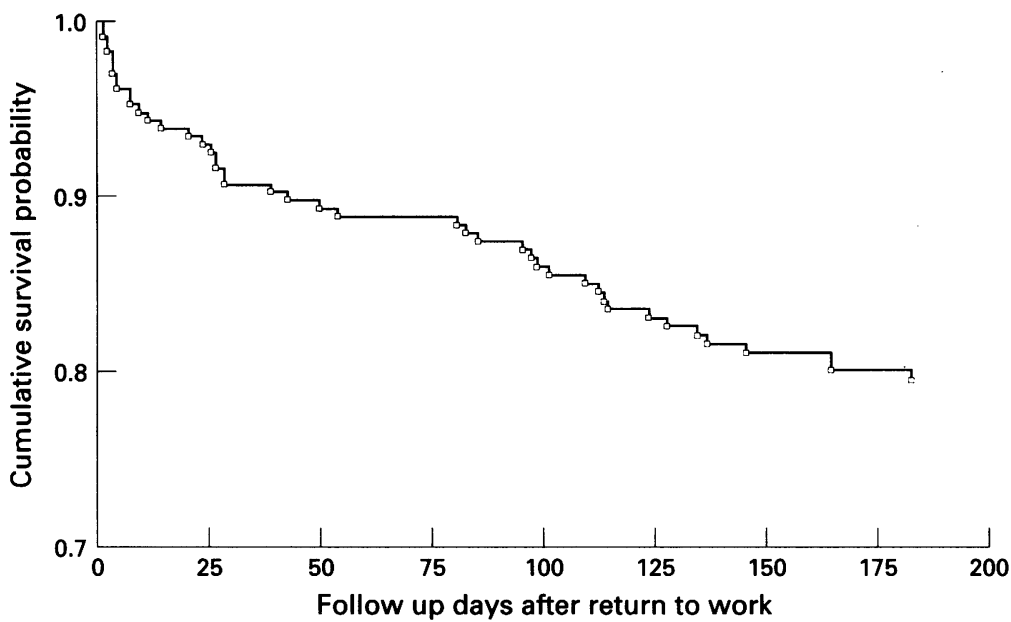

Probability of relapse or first short sickness absence for back pain by time since return to work. to our definition and $50 \%$ had it within 42 days of returning to work. Fifteen additional workers $(6.5 \%)$ first had a short sickness absence due to back pain; among those, 11 went on to the end of the study without relapse and four were eventually lost to follow up; of these four, two were lost to the study at 71 days, and the two others at 111 and 133 days. Five additional short sickness absences were reported, but those events were not analysed as they were not independent of previous absences. Among the 230 workers who returned to work, $155(67 \cdot 3 \%)$ had neither a relapse nor a short sickness absence due to back pain. Finally, 31 workers returned to work but were lost to follow up before relapse, short sickness absence or the end of the study; their median follow up time was 71 days and some were lost close to the end of the study at 176 days.

The cumulative probability of relapse or first short sickness absence due to back pain was estimated with a Kaplan-Meier curve (figure) according to follow up days after return to work. The curve showed rapid decline during the first 25 days. The probability of not having a relapse or a short sickness absence due to back pain remained stable between 25 and 75 days after return to work when it started to decline again. The last observed event which was a short sickness absence for back pain took place on day 182 .

Distribution of those who relapsed, had a short sickness absence, had neither of these outcomes, or were lost to follow up is shown for age, sex, and some work characteristics (table 2). In comparison with those who relapsed, there were proportionally more women, more workers from private and large entreprises, and more part time workers lost to follow up. The pain score on the visual analog scale was lower in the workers lost to follow up than in those who relapsed.

A maximum of $10 \%$ of workers reported much pain or pain which made daily movements impossible (the two highest categories

Table 1 shows the incidence of events and extent of follow up in each group. Twenty nine workers $(12 \cdot 6 \%)$ had a relapse according

Table 2 Workers who relapsed or had short sickness absence due to back pain according to work environment characteristics

\begin{tabular}{|c|c|c|c|c|c|}
\hline Characteristic & $\begin{array}{l}\text { Subjects } \\
\text { (n) }\end{array}$ & $\begin{array}{l}\text { Relapse } \\
(n(\%))\end{array}$ & $\begin{array}{l}\text { First } \\
\text { short sickness } \\
\text { absence } \\
(n(\%))\end{array}$ & $\begin{array}{l}\text { Neither relapse } \\
\text { nor short } \\
\text { sickness absence } \\
(n(\%))\end{array}$ & $\begin{array}{l}\text { Lost to follow up } \\
(n(\%))\end{array}$ \\
\hline $\begin{array}{l}\text { Age (mean (SD)) } \\
\text { Visual analog pain score (mean (SD)) }\end{array}$ & $\begin{array}{l}230 \\
210\end{array}$ & $\begin{array}{c}34 \cdot 9(12 \cdot 2) \\
4 \cdot 0(3 \cdot 1)\end{array}$ & $\begin{array}{c}29 \cdot 5(10 \cdot 2) \\
3 \cdot 3(1 \cdot 9)\end{array}$ & $\begin{array}{c}35 \cdot 5(10 \cdot 9) \\
2 \cdot 7(2 \cdot 1)\end{array}$ & $\begin{aligned} 34.8(13.5) \\
2 \cdot 8(2 \cdot 6)\end{aligned}$ \\
\hline \multicolumn{6}{|l|}{ Sex: } \\
\hline $\begin{array}{l}\text { Men } \\
\text { Women }\end{array}$ & $\begin{array}{r}167 \\
63\end{array}$ & $\begin{array}{r}20(12 \cdot 0) \\
9(14 \cdot 3)\end{array}$ & $\begin{array}{r}13(7 \cdot 8) \\
2(3 \cdot 2)\end{array}$ & $\begin{array}{r}114(68 \cdot 3) \\
41(65 \cdot 1)\end{array}$ & $\begin{array}{l}20(12 \cdot 0) \\
11(17 \cdot 5)\end{array}$ \\
\hline \multicolumn{6}{|l|}{ Type of enterprise: } \\
\hline $\begin{array}{l}\text { Public } \\
\text { Private }\end{array}$ & $\begin{array}{r}76 \\
149\end{array}$ & $\begin{array}{l}11(14 \cdot 5) \\
18(12 \cdot 1)\end{array}$ & $\begin{array}{l}7(9 \cdot 2) \\
7(4 \cdot 7)\end{array}$ & $\begin{array}{l}55(72 \cdot 4) \\
97(65 \cdot 1)\end{array}$ & $\begin{array}{c}3(3 \cdot 9) \\
27(18 \cdot 1)\end{array}$ \\
\hline \multicolumn{6}{|l|}{$\begin{array}{l}\text { Duration of employment in the } \\
\text { industry (months): }\end{array}$} \\
\hline $\begin{array}{l}\quad \leqslant 24 \\
\quad>24 \\
\text { Salary insurance: }\end{array}$ & $\begin{array}{r}90 \\
140\end{array}$ & $\begin{array}{l}12(13 \cdot 3) \\
17(12 \cdot 1)\end{array}$ & $\begin{array}{l}6(6 \cdot 7) \\
9(6 \cdot 4)\end{array}$ & $\begin{array}{l}59(65 \cdot 6) \\
96(68 \cdot 6)\end{array}$ & $\begin{array}{l}13(14 \cdot 4) \\
18(12 \cdot 9)\end{array}$ \\
\hline Yes & 137 & $15(10 \cdot 9)$ & $12(8 \cdot 8)$ & $94(68 \cdot 6)$ & $16(11 \cdot 7)$ \\
\hline No & 80 & $13(16 \cdot 3)$ & $2(2 \cdot 5)$ & $52(65 \cdot 0)$ & $13(16 \cdot 3)$ \\
\hline \multicolumn{6}{|l|}{ Size of the industry (employees (n)): } \\
\hline $\begin{array}{l}<100 \\
\geqslant 100\end{array}$ & $\begin{array}{r}76 \\
151\end{array}$ & $\begin{array}{l}13(17 \cdot 1) \\
16(10 \cdot 6)\end{array}$ & $\begin{array}{r}5(6 \cdot 6) \\
10(6 \cdot 6)\end{array}$ & $\begin{array}{r}49(64 \cdot 5) \\
103(68 \cdot 2)\end{array}$ & $\begin{array}{r}9(11 \cdot 8) \\
22(14 \cdot 6)\end{array}$ \\
\hline \multicolumn{6}{|l|}{ Status of employment: } \\
\hline Occasional & 14 & $\begin{array}{l}2(14 \cdot 3) \\
1(7 \cdot 1)\end{array}$ & $\begin{array}{l}0(0 \cdot 0) \\
0(0 \cdot 0)\end{array}$ & $\begin{array}{r}11(78 \cdot 6) \\
9(64 \cdot 3)\end{array}$ & $\begin{array}{l}1(7 \cdot 1) \\
4(28 \cdot 6)\end{array}$ \\
\hline Full time & 202 & $26(12 \cdot 99)$ & $15(7 \cdot 4)$ & $135(66 \cdot 8)$ & $26(12 \cdot 9)$ \\
\hline
\end{tabular}

Missing values are not compensated for. 
Table 3 Univariate Cox's regression analysis of functional capacity and pain scale variables: RRs (95\% CIs) and P values for the -2 log likelihood statistic

\begin{tabular}{|c|c|c|c|}
\hline \multirow[b]{2}{*}{ Variable (subjects (n)) } & \multicolumn{3}{|l|}{ Outcome } \\
\hline & Relapse & $\begin{array}{l}\text { First short } \\
\text { sickness absence } \\
\text { due to back pain }\end{array}$ & $\begin{array}{l}\text { Relapse and first } \\
\text { short sickness } \\
\text { absence } \\
\text { due to back pain }\end{array}$ \\
\hline \multicolumn{4}{|l|}{ Wait standing up (209): } \\
\hline RR & $1 \cdot 35$ & $1 \cdot 20$ & $1 \cdot 29$ \\
\hline $95 \% \mathrm{CI}$ & 0.90 to 2.00 & 0.68 to 2.11 & 0.93 to 1.79 \\
\hline$P$ value & $0 \cdot 15$ & 0.51 & $0 \cdot 12$ \\
\hline \multicolumn{4}{|l|}{ Wash at sink (209): } \\
\hline RR & $1 \cdot 40$ & $1 \cdot 25$ & $1 \cdot 35$ \\
\hline $95 \% \mathrm{CI}$ & 0.91 to 2.13 & 0.68 to 2.30 & 0.95 to 1.91 \\
\hline P value & $0 \cdot 13$ & 0.47 & $0 \cdot 10$ \\
\hline \multicolumn{4}{|l|}{ Sleep (210): } \\
\hline RR & 1.69 & $1 \cdot 48$ & 1.61 \\
\hline $95 \% \mathrm{CI}$ & $1 \cdot 18$ to $2 \cdot 42$ & 0.88 to $2 \cdot 49$ & $1 \cdot 20$ to $2 \cdot 17$ \\
\hline$P$ value & 0.007 & $0 \cdot 16$ & 0.002 \\
\hline \multicolumn{4}{|l|}{ Walk (210): } \\
\hline RR & 1.61 & $1 \cdot 50$ & 1.57 \\
\hline $95 \% \mathrm{CI}$ & 1.07 to 2.43 & 0.84 to 2.66 & $1 \cdot 12$ to $2 \cdot 19$ \\
\hline$P$ value & 0.03 & $0 \cdot 18$ & 0.01 \\
\hline \multicolumn{4}{|c|}{ Go up and down the stairs (201): } \\
\hline$R R$ & 1.91 & $1 \cdot 73$ & $1 \cdot 85$ \\
\hline $95 \% \mathrm{CI}$ & $1 \cdot 36$ to $2 \cdot 70$ & 1.08 to 2.79 & 1.40 to 2.44 \\
\hline$P$ value & 0.0004 & 0.03 & 0.0000 \\
\hline \multicolumn{4}{|c|}{ Watch TV or be seated $(210)$ : } \\
\hline$R R$ & $1 \cdot 38$ & 1.54 & 1.43 \\
\hline $95 \% \mathrm{CI}$ & 0.94 to 2.02 & 0.93 to 2.53 & 1.06 to 1.94 \\
\hline$P$ value & $0 \cdot 10$ & $0 \cdot 10$ & 0.02 \\
\hline \multicolumn{4}{|c|}{ Put on socks or shoes (210): } \\
\hline $\mathrm{RR}$ & $1 \cdot 29$ & $1 \cdot 43$ & $1 \cdot 34$ \\
\hline $95 \% \mathrm{CI}$ & 0.84 to 1.97 & 0.83 to 2.48 & 0.96 to 1.88 \\
\hline $\begin{array}{l}\text { P value } \\
\text {. }\end{array}$ & $0 \cdot 24$ & $0 \cdot 21$ & 0.09 \\
\hline \multicolumn{4}{|l|}{ Put on shirt (210): } \\
\hline RR & 1.91 & $2 \cdot 81$ & $2 \cdot 22$ \\
\hline $95 \%$ CI & 0.91 to 3.98 & 1.23 to 6.38 & 1.29 to 3.83 \\
\hline$P$ value & $0 \cdot 12$ & 0.03 & 0.01 \\
\hline \multicolumn{4}{|c|}{ Pick up an object from the } \\
\hline floor (208): & & & \\
\hline RR & 1.45 & 1.50 & 1.47 \\
\hline $95 \% \mathrm{CI}$ & 1.02 to 2.07 & 0.93 to 2.41 & 1.10 to 1.95 \\
\hline P value & 0.05 & 0.11 & 0.01 \\
\hline \multicolumn{4}{|c|}{$\begin{array}{l}\text { Putting things away above the } \\
\text { shoulders }(189) \text { : }\end{array}$} \\
\hline$R R$ & 1.66 & 1.52 & 1.62 \\
\hline $95 \% \mathrm{CI}$ & $1 \cdot 15$ to $2 \cdot 41$ & 0.89 to 2.62 & $1 \cdot 19$ to $2 \cdot 19$ \\
\hline P value & 0.01 & $0 \cdot 15$ & 0.004 \\
\hline \multicolumn{4}{|l|}{ Pain scale (210): } \\
\hline RR & $1 \cdot 23$ & $1 \cdot 10$ & $1 \cdot 19$ \\
\hline $95 \%$ CI & 1.06 to 1.44 & 0.88 to 1.38 & 1.05 to 1.35 \\
\hline$P$ value & 0.008 & 0.38 & 0.008 \\
\hline \multicolumn{4}{|c|}{$\begin{array}{l}\text { Principal component pain } \\
\text { scale }(230))^{\star}\end{array}$} \\
\hline RR & $1 \cdot 79$ & $1 \cdot 72$ & $1 \cdot 76$ \\
\hline $95 \% \mathrm{CI}$ & 1.24 to 2.57 & 1.02 to 2.87 & 1.31 to 2.37 \\
\hline P Value & 0.003 & 0.05 & 0.0001 \\
\hline
\end{tabular}

${ }^{\star}$ Includes all functional capacity variables as well as the analog pain scale: missing values are replaced by the mean value for the variable.

on the scale), and that proportion was reached for the variable "wait standing up"; $8.4 \%$ reported the same levels of pain for "going up and down the stairs", and $7 \cdot 6 \%$ for "watching TV or being seated"; for all other variables (table 3), the proportion reporting that degree of pain was between $3 \%$ and $6 \%$. On the visual analog pain scale ranging from 0 to 10 , the mean ( $S D$, median) score was $2.9(2.3$, $3 \cdot 0)$. Eighty seven per cent of workers indicated a score of 5 or less; six workers gave a score of 6,12 a score of 7 , and eight a score of 8 to 10 .

Whether functional capacity and pain variables were categorised or put in the analysis as numerical variables did not change the interpretation of results so we used numerical variables. Table 3 shows that RRs for all outcomes increased with level of pain although this increase was not always significant. For a relapse, going up and down the stairs, pain associated with sleep, and the pain scale were the variables which contributed most to the fit of the data. Both movement variables (walking, going up and down the stairs) contributed, as did one variable related to raising the arms (putting things away above the shoulders); however, the contribution of flexion variables was not strong (washing at the sink, putting on socks, and picking up an object from the floor). For the first short sickness absence, RRs, although rarely significant, were all in the same direction as those for relapse. For relapse or first short sickness absence due to back pain, most variables made a significant contribution to the fit of the data, except waiting standing up and washing at the sink, which were marginally significant.

In an effort to reduce the number of variables and because the functional capacity variables and the visual analog pain scale variable were highly correlated (with a Kendall $\tau$ statistic, correlations were in the order of 0.40 to 0.49 between each functional capacity variable and the pain scale, and $P$ values were all $<0.000$ ), a principal component analysis was carried out with all the functional capacity variables and the pain scale; it yielded a Kayser-Meyer-Olkin measure of sampling adequacy of 0.916 and a Bartlett test of sphericity of 967.7 with a significance of $<0.000$. The first component which could be defined as "pain related to functional capacity" captured $52.2 \%$ of the variance with an eigenvalue of 5.74 ; the second component explained only $7 \cdot 7 \%$ of the variance with an eigenvalue of 0.85 and was not retained. A score based on the first component was estimated; although its units are not directly interpretable, as the score increases pain is worse. The factor loadings which are the correlations between the variables and the factor ranged between 0.63 to 0.81 . The last column of table 3 shows the score RRs for relapse and first short sickness absence.

Next, we considered demographic and clinical variables (table 4). For relapse, the following variables did make a significant contribution: limitations in movement amplitude as reported by the physician, measured flexion, number of days between beginning of treatment and return to work, medical restrictive advice, and to a more marginal extent, radiating pain and nature of diagnosis. For the first short sickness absence, none of the variables contributed to the fit of the data; the risk associated with radiating pain was low, measured flexion seemed to bear no relation with this outcome, and a longer interval between the beginning of treatment and return to work seemed protective whereas it was a clear risk factor for relapse.

Table 5 shows the changes in the work situation on return to work. Only 14 workers out of the $148(9.5 \%)$ who returned to the same industry and the same job reported changes in the work conditions. Among the 230 who returned to work, 63 either changed industry, or job, or both.

When relating variables of changing job to the studied outcomes (table 6), we found a somewhat different picture for the two outcomes; changing job because of back pain was associated with an increased risk of relapse as well as being of the opinion that one should have been offered another job, and (to a lesser 
Table 4 Univariate Cox's regression analysis of demographic and clinical observations at discharge: RRs (95\% CIs) and $P$ values for the -2 log likelihood statistic

\begin{tabular}{|c|c|c|c|}
\hline \multirow[b]{2}{*}{ Variable (subjects $(n))$} & \multicolumn{3}{|l|}{ Outcome } \\
\hline & Relapse & $\begin{array}{l}\text { First short } \\
\text { sickness absence } \\
\text { due to back pain }\end{array}$ & $\begin{array}{l}\text { Relapse and first } \\
\text { short sickness } \\
\text { absence } \\
\text { due to back pain }\end{array}$ \\
\hline \multicolumn{4}{|l|}{ Age (y): } \\
\hline$>30(129)(R R)$ & 1.00 & 1.00 & 1.00 \\
\hline $\begin{array}{l}\leqslant 20(23)(\operatorname{RR}(95 \% \mathrm{CI})) \\
21-30(78)(\operatorname{RR}(95 \% \mathrm{CI}))\end{array}$ & $\begin{array}{l}1.64(0.54 \text { to } 4.92) \\
1.02(0.45 \text { to } 2.32)\end{array}$ & & $\begin{array}{l}2.39(1.06 \text { to } 5.37) \\
1.16(0.59 \text { to } 2.27)\end{array}$ \\
\hline$P$ value & 0.69 & $0 \cdot 10$ & $0 \cdot 14$ \\
\hline \multicolumn{4}{|l|}{ Sex: } \\
\hline Women (63) (RR (95\% CI)) & $1.23(0.56$ to 2.70$)$ & $0.42(0.09$ to 1.88$)$ & $0.91(0.46$ to 1.81$)$ \\
\hline $\operatorname{Men}(167)(R R)$ & $1 \cdot 0$ & $1 \cdot 0$ & 1.00 \\
\hline$P$ value & $0 \cdot 60$ & $0 \cdot 21$ & $0 \cdot 80$ \\
\hline \multicolumn{4}{|l|}{ Diagnosis: } \\
\hline Disc disorder (14) (RR) & 1.00 & 1.00 & $1 \cdot 00$ \\
\hline Pain or sprain (207) (RR (95\% CI)) & $0.28(0.09$ to 0.81$)$ & $0.64(0.08$ to 4.97$)$ & $0.35(0.13$ to 0.90$)$ \\
\hline Other (7) (RR (95\% CI)) & $0.79(0.14$ to $4 \cdot 34)$ & $1.59(0.09$ to 25.48$)$ & $0.95(0.22$ to 3.99$)$ \\
\hline$P$ value & $0 \cdot 07$ & 0.70 & 0.06 \\
\hline \multicolumn{4}{|l|}{ Radiating pain: } \\
\hline Yes (32) (RR (95\% CI)) & $2 \cdot 22(0.95$ to $5 \cdot 21)$ & $1.07(0.24$ to 4.74$)$ & $1.79(0.86$ to 3.73$)$ \\
\hline No $(197)$ & $1 \cdot 0$ & $1 \cdot 0$ & 1.00 \\
\hline$P$ value & 0.08 & 0.92 & $0 \cdot 14$ \\
\hline \multicolumn{4}{|l|}{ Neurological symptoms: } \\
\hline Yes (16) (RR (95\% CI)) & $1 \cdot 06(0.25$ to $4 \cdot 46)$ & $2 \cdot 21(0.49$ to $9 \cdot 79)$ & $1.43(0.51$ to 4.00$)$ \\
\hline No $(212)(R R)$ & $1 \cdot 0$ & $1 \cdot 0$ & 1.00 \\
\hline$P$ value & 0.93 & $0 \cdot 34$ & 0.51 \\
\hline \multicolumn{4}{|l|}{$\begin{array}{l}\text { Movement amplitude limitations } \\
\text { according to the physician: }\end{array}$} \\
\hline Yes $(84)(R R(95 \%$ CI $))$ & $2 \cdot 82(1.32$ to 6.03$)$ & $1.22(0.43$ to $3 \cdot 44)$ & $2 \cdot 10(1 \cdot 15$ to $3 \cdot 83)$ \\
\hline No $(142)(R R)$ & $1 \cdot 0$ & 1.0 & 1.00 \\
\hline$P$ value & 0.006 & $0 \cdot 70$ & 0.01 \\
\hline \multicolumn{4}{|l|}{ Medical restrictive advice: } \\
\hline Yes (33) (RR (95\% CI)) & $2.38(1.06$ to 5.35$)$ & $2.27(0.77$ to 6.66$)$ & $2.34(1.23$ to 4.47$)$ \\
\hline No $(166)(R R)$ & $1 \cdot 0$ & $1 \cdot 0$ & 1.00 \\
\hline$P$ value & 0.04 & $0 \cdot 15$ & 0.01 \\
\hline \multicolumn{4}{|l|}{ Measured flexion: } \\
\hline Good (50) (RR) & 1.00 & 1.00 & $1 \cdot 00$ \\
\hline Low (100) (RR (95\% CI)) & $3.39(0.76$ to 15.02$)$ & $1.05(0.26$ to $4 \cdot 20)$ & $1.98(0.74$ to 5.32$)$ \\
\hline Poor (50) (RR (95\% CI)) & $6.03(1.33$ to 27.21$)$ & $0.73(0.12$ to $4 \cdot 39)$ & $2.85(1.01$ to 8.00$)$ \\
\hline$P$ value & 0.02 & 0.89 & $0 \cdot 10$ \\
\hline \multicolumn{4}{|l|}{$\begin{array}{l}\text { Number of days between beginning of } \\
\text { treatment and return to work: }\end{array}$} \\
\hline$>60(155)(\mathrm{RR}(95 \% \mathrm{CI}))$ & $3 \cdot 20(1 \cdot 11$ to $9 \cdot 22)$ & $0.77(0 \cdot 27$ to $2 \cdot 17)$ & $1.74(0.86$ to 3.45$)$ \\
\hline$\leqslant 60(75)(R R)$ & $1 \cdot 0$ & $1 \cdot 0$ & 1.00 \\
\hline$P$ value & 0.01 & 0.63 & $0 \cdot 10$ \\
\hline
\end{tabular}

extent) thinking that the work should have been physically modified. For short sickness absence, changing job because of back pain seemed a protective factor; wishing that some tasks were eliminated, or to be allowed to do less seemed to have a greater impact on the risk of short sickness absence than thinking that another job should have been offered.

A final multivariate model was developed; because of the few subjects with either relapse or first short sickness absence, only a model combining these two outcomes as the dependent variable was used; as studying the effect of pain (overall and when doing simple movements) at discharge was the main objective of

Table 5 Descriptive data on changes in work situation upon return to work

\begin{tabular}{ll}
\hline Work situation & Subjects $(n)$ \\
\hline Returned to work & 230 \\
Same industry, same job & 148 \\
Change in working conditions & 14 (6 found them satisfactory) \\
No change in working conditions: & 134 \\
Reported difficulties in those 134 workers: & 74 \\
None & 40 \\
Minor & 17 \\
Some & 3 \\
A lot & 63 \\
Changes: & 36 \\
Same industry, different job & 3 \\
Different industry, same job & 24 \\
Different industry and job & 24 \\
Change due to back pain in the 63 workers with changes: & 24 \\
Yes & 34 \\
No & 3 \\
Partially & 2 \\
Other reasons & 19 \\
\hline Unknown & \\
\hline
\end{tabular}

the study, the pain score was forced into the model; then we considered work conditions and clinical variables separately because of the problem of collinearity. Variables which were significant $(P \leqslant 0 \cdot 10)$ for either outcome in previous univariate analyses were included in the model. In either model, pain was the only variable that maintained discriminatory power for the studied outcome; in the clinical model the RR $(95 \% \mathrm{CI})$ for the pain score was 1.53 $(0.96$ to 2.43$)$ and in the changing job model, it was $1.60(1.08$ to 2.36$)$.

\section{Discussion}

It is difficult to compare the results of this study with the few others which have been published, because the definition of the outcome was different in all studies and the workers included in the studies had different backgrounds with respect to back pain, as well as different levels of severity at entry. Nevertheless, incidence figures for relapse or recurrence were not so different; there was a $21 \%$ recurrence rate in the first six months in the study of Berquist-Ullman and Larsson ${ }^{3}$ : $44 \%$ of workers had sickness absence in the year after examination in the study of Troup et $a l^{4} ; 22 \%$ of workers were compensated again in the year after they had been in the compensation files in the study of Abenhaim et al ; and finally, we estimated a $19 \%$ rate of absenteism due to back pain lasting three days 
Table 6 Univariate Cox's regression analysis of reasons for work change and workers' opinions on necessary changes to working conditions: RRs (95\% CIs) and P values for the -2 log likelihood statistic

\begin{tabular}{|c|c|c|c|}
\hline \multirow[b]{2}{*}{ Variable (subjects $(n))$} & \multicolumn{3}{|l|}{ Outcome } \\
\hline & Relapse & $\begin{array}{l}\text { First short } \\
\text { sickness absence } \\
\text { due to back pain }\end{array}$ & $\begin{array}{l}\text { Relapse and first } \\
\text { short sickness } \\
\text { absence } \\
\text { due to back pain }\end{array}$ \\
\hline $\begin{array}{l}\text { Changed job or company: } \\
\text { No (148) (RR) }\end{array}$ & $1 \cdot 00$ & $1 \cdot 00$ & $1 \cdot 00$ \\
\hline $\begin{array}{l}\text { Because or back pain }(27) \\
(\mathrm{RR}(95 \% \mathrm{CI}))\end{array}$ & $2 \cdot 83(1.17$ to $6 \cdot 84)$ & $0.63(0.08$ to 4.90$)$ & $1.97(0.89$ to 4.33$)$ \\
\hline Other reasons (36) (RR (95\% CI)) & $0.76(0.22$ to $2 \cdot 61)$ & $1.17(0.32$ to $4 \cdot 22)$ & $0.92(0.38$ to 2.24$)$ \\
\hline$P$ value & 0.07 & $0 \cdot 85$ & 0.25 \\
\hline \multicolumn{4}{|l|}{ I should have been offered another job: } \\
\hline $\begin{array}{l}\text { Yes }(16)(\mathrm{RR}(95 \% \mathrm{CI})) \\
\text { No }(192)(\mathrm{RR})\end{array}$ & $\begin{array}{l}5.00(2 \cdot 00 \text { to } 12 \cdot 48) \\
1.0\end{array}$ & $\begin{array}{l}2 \cdot 78(0 \cdot 62 \text { to } 12 \cdot 46) \\
1 \cdot 0\end{array}$ & $4 \cdot 17(1.92$ to $9 \cdot 06)$ \\
\hline $\begin{array}{l}\text { No }(192)(\mathrm{RR}) \\
\text { P value }\end{array}$ & $\begin{array}{l}1 \cdot 0 \\
0.003\end{array}$ & $\begin{array}{l}1 \cdot 0 \\
0 \cdot 23\end{array}$ & $\begin{array}{l}1.00 \\
0.001\end{array}$ \\
\hline \multicolumn{4}{|l|}{$\begin{array}{l}\text { They should have physically modified } \\
\text { the job: }\end{array}$} \\
\hline $\begin{array}{l}\text { Yes }(14)(R R(95 \% \text { CI })) \\
\text { No }(195)(R R)\end{array}$ & $\begin{array}{l}3.02(1.04 \text { to } 8 \cdot 79) \\
1.0\end{array}$ & $\begin{array}{l}2.52(0.56 \text { to } 11 \cdot 20) \\
1.0\end{array}$ & $\begin{array}{l}2 \cdot 83(1 \cdot 19 \text { to } 6 \cdot 75) \\
1.00\end{array}$ \\
\hline$P$ value & $0 \cdot 07$ & 0.27 & 0.03 \\
\hline \multicolumn{4}{|l|}{ They should have eliminated some tasks: } \\
\hline $\begin{array}{l}\text { Yes }(16)(R R(95 \% C I)) \\
\text { No }(192)(R R)\end{array}$ & $\begin{array}{l}2.75(0.94 \text { to } 8.01) \\
1.0\end{array}$ & $\begin{array}{l}6 \cdot 13(1.91 \text { to } 19 \cdot 62) \\
1.0\end{array}$ & $\begin{array}{l}3 \cdot 80(1 \cdot 75 \text { to } 8 \cdot 27) \\
1.00\end{array}$ \\
\hline$P$ value & 0.09 & $0 \cdot 008$ & 0.003 \\
\hline \multicolumn{4}{|l|}{$\begin{array}{l}\text { They should have allowed me to do } \\
\text { less and pause more: }\end{array}$} \\
\hline Yes $(24)($ RR $(95 \%$ CI) $)$ & $2 \cdot 12(0 \cdot 80$ to $5 \cdot 65)$ & $3.24(1.03$ to 10.18$)$ & $2 \cdot 51(1.19$ to $5 \cdot 26)$ \\
\hline No $(184)(R R)$ & $1 \cdot 0$ & 1.0 & 1.00 \\
\hline$P$ value & $0 \cdot 16$ & 0.06 & 0.02 \\
\hline
\end{tabular}

(relapse) or less (short sickness absence) within the first six months after return to work.

In our study, we are not sure if all relapses were new episodes; although average time to return to work from onset of treatment was very long (126 days), the shape of the cumulative survival curve suggested that some relapses or interruptions may have been due to untimely returns. The fact that a small but non-negligible percentage of workers reported considerable pain while carrying out simple daily movements at the end of the treatment period increases the likelihood that the episode had not subsided. On the other hand, there were similarities with the timing of relapses between our study and the one by Ullman and Larsson, ${ }^{3}$ in which they made sure to count a recurrence only if the original episode had subsided; $50 \%$ of recurrences in their study occurred within two months, whereas in our study, $50 \%$ of patients who relapsed did so within 42 days after return to work, and $50 \%$ who had a first short sickness absence due to back pain did so within 28 days; for these two outcomes together the median time was 40 days.

Rate ratios for functional capacity variables and the pain scale were comparable for relapse and first short sickness absence considered separately, even though the contribution to the fit of the data was not as good for short sickness absence. It was puzzling, however, to find that among the functional capacity variables, those describing flexion-for example, putting on socks, picking up an object from the floorwere not strongly predictive of relapse, whereas variables referring to the same concept, but measured differently-for example, limitations in movement amplitude as measured by the physician, and flexion measured by the physiotherapist-were strong predictors.

Relapse was not predicted by the same clinical variables as first short sickness absence. For instance, younger age was a strong predictor of short sickness absence whereas it was not for relapse; duration between onset of treatment and return to work did not seem to affect the probability of short sickness absence whereas it did considerably affect that of relapse. Some prudence is required, however, in the interpretation of these results as numbers of subjects with the respective outcomes were small. This was reflected in the wide confidence intervals accompanying the rate ratios. It may be useful to plan future studies with adequate power for each of these outcomes.

The probability of relapse was associated with an expressed wish on the part of the workers for a new job or for physical modifications to the current one whereas the probability of short sickness absence was related to wishes to suppress some tasks as well as to do less. Despite these differences, the expressed needs on returning to work seemed to be useful predictors of recurrence, at least in the univariate analysis. It is relevant to recall that these wishes were expressed by most workers before the occurrence of relapse or short sickness absence. Nevertheless, when assessed with the pain scale, these variables no longer contributed. Pain seemed to capture the expression of all other variables, whether clinical or related to personal views on the type of work.

One of the striking findings in this study is the importance of disruption to the working life associated with back pain, even though it is a first episode. From the analysis of return to work, ${ }^{6}$ we concluded that possibly as many as $12 \%$ of workers did not return to work after a follow up lasting between 213 and 1228 days, and an additional $6 \%$ went into retirement or vocational training after a maximum follow up period of 880 days. Also, the present analysis shows that 63 workers changed job, or company, or both. In summary, this first episode of back pain resulted in important changes in the working life of 121 workers out of the original $305(39 \cdot 6 \%)$, and only 114 workers returned to the same company and the same job without reporting some or a lot of difficulties. 
Although Vällfors ${ }^{8}$ had reported that only minor modifications were made to working conditions after an episode of back pain, we hypothesised that this situation would improve as the problem of occupational back pain took on phenomenal proportions in terms of incidence and cost. However, this study shows that only a negligable proportion of workers reported modifications to working conditions; also, these were not often satisfactory in the short term, which may not encourage employers to offer them. We do not know if these changes would have an influence in the long term. It seemed that workers chose to change job or company to try to prevent relapse.

It is understandable that therapists do not have the means or the resources to systematically intervene in the workplace to change working conditions; however, it would seem reasonable to suggest that the state, which recognises the health problem, compensates it, and pays for its treatment, gives itself further means (or reviews its resource allocation between treatment and workplace intervention) to facilitate return to work. Target workers could be those reporting pain, after treatment, with simple daily movements as measured in this study. Comparison of the incidence of relapse in experimental studies between those with and without modifications to their working conditions could be carried out and provide useful results.

In most cohorts of workers with back pain actively followed up with individual and repeated measures, losses to follow up are substantial. The percentage of losses to return to work in this study was among the lowest. ${ }^{6}$ After return to work, other workers were lost to follow up; however, only 13 workers $(5 \cdot 6 \%)$ were lost in the first 45 days after return to work when the chance of relapse was high. Some of the characteristics of the workers lost to follow up were associated with a lower incidence of relapse (large enterprise, part time worker), but others with a higher incidence (being female). In the end, it is difficult to determine if those losses resulted in an overestimate or underestimate of the incidence of relapse. The effect of pain on relapse was probably overestimated because those lost to follow up had lower pain levels.

The study had limited power to detect prognostic factors because of the small absolute number of relapses and short sickness absences. This is why the results must be interpreted with caution. In particular, a further exploration of the contribution of working conditions (changed or unchanged) on the incidence of relapse is warranted.

In conclusion, this study indicates that the rate of relapse within the first six months of return to work is high even among workers with a first episode of back pain; that relapse occurs within 42 days for $50 \%$ of the workers; that reported pain while carrying out simple daily movements at the end of the treatment period is prognostic of relapse and of short sickness absences due to back pain; that modifications to the work environment are very rare and minor; and finally, that an episode of back pain has a serious impact on the working life as a large proportion of patients do not return to work but retire, retrain, or change jobs. Multicentre studies with standardised measures and large sample sizes are needed to study, from incidence of relapse, the history of back pain among workers.

This project was supported by a grant from the Institut de This project was supported by a grant from the Institut de Luce Duval (Hôpital Champlain de Verdun) and Diane Milot for data collection.

1 Von Korff $M$. Studying the natural history of back pain Spine 1994:19:2041S-6S.

2 Frymoyer JW. Back pain and sciatica. N Engl f Med 1988 318:291-300.

3 Bergquist-Ullman $M$, Larsson U. Acute low back pain in industry: a controlled prospective study with special refScand Suppl 1977;170:1-177.

4 Troup JDG, Martin JW, Lloyd DCEF. Back pain in industry: a prospective study. Spine 1981;6:61-9.

5 Abenhaim L, Suissa S, Rossignol M. Risk recurrence of

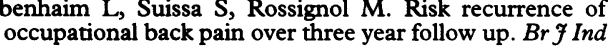
Med 1988;45:829-33.

6 Infante-Rivard C, Lortie M. Prognostic factors for return to work after a first compensated episode of back pain. Occup Environ Med 1996;53:488-94.

7 McDowell I, Newell C. Measuring health. New York: Oxford University Press, 1987:235-9.

8 Vällfors B. Acute, subacute and chronic low back pain clinical symptoms, absenteeism and working environment. Scand $\mathcal{F}$ Rehabil Med Suppl 1985;11:1-98. 